Relato de Experiência

\title{
Consulta de Enfermagem - um diálogo entre os saberes técnicos e populares em saúde
}

\author{
Dialogue between nurses and mothers during the mother-child binomial consultantion
}

Consulta de Enfermería - un diálogo cultural entre los saberes técnicos y populares en salud

\section{Maria Aparecida Rodrigues da Silva Barbosa ${ }^{1}$, Neuma Zamariano Fanaia Teixeira ${ }^{2}$, Wilza Rocha Pereira ${ }^{3}$}

\section{RESUMO}

Neste relato de experiência evidenciamos algumas estratégias que fizeram da consulta de enfermagem ao binômio mãe-filho um espaço privilegiado para o diálogo com a cultura e os saberes da população assistida. A técnica da coleta de dados foi o registro, durante seis meses, em diários de campo, das impressões verbalizadas pelas mulheres sobre o atendimento recebido. Demos o mesmo tratamento às nossas percepções e impressões. Escolhemos 30 registros de mulheres que freqüentaram o serviço regularmente e, a partir desses depoimentos, fomos introduzindo alterações no modelo de consulta. Pudemos compreender, a partir da experiência, que é fundamental o estabelecimento de uma relação dialógica entre os saberes populares e acadêmicos para o cuidado humanizado e eficiente em saúde.

Descritores: Enfermagem materno-infantil; Assistência ambulatorial; Educação em saúde

\begin{abstract}
To describe strategies that might promote technical and cultural and common knowledge dialogue between nurses and mothers during the mother-child binomial nursing consultation. A purposive sample of 30 women who had regular nursing consultation appointment was used. Data were collected throughout a period of 6 months and consisted of taking notes of verbal discussions with women regarding their experiences with mother-child binomial nursing care. Data were recorded using field diary. The model of nursing care was modified during data collection to attend the mother-child binominal needs. Strategies to modify the model of nursing care to enhance dialogue between nurses and the mother-child binomial might be essential to improve efficacy and humanization of nursing care.
\end{abstract}

Keywords: Maternal-child nursing; Ambulatory care; Health education

\section{RESUMEN}

En este relato de experiencia evidenciamos algunas estrategias que hicieron de la Consulta de Enfermería, con el binomio madre-niño, un espacio privilegiado para el diálogo con la cultura y los saberes de la población asistida. La técnica de recolección de datos fue el registro, durante seis meses, en diarios de campo, de las impresiones verbalizadas por las mujeres sobre la atención recibida. Dimos el mismo trato a nuestras percepciones e impresiones. Escogimos 30 registros de mujeres que frecuentaron el servicio regularmente y, a partir de esos testimonios, fuimos introduciendo alteraciones en el modelo de consulta. Pudimos comprender, a partir de esa experiencia, que es fundamental el establecimiento de una relación dialógica entre los saberes populares y académicos para el cuidado humanizado y eficiente en salud. Descriptores: Enfermería materno-infantil; Asistencia ambulatoria; Educación en salud

\footnotetext{
${ }^{1}$ Professora da Faculdade de Enfermagem da Universidade Federal de Mato Grosso - UFMS - Campo Grande, (MS), Brasil. Membro do Grupo de Pesquisa ARGOS - Campo Grande (MS), Brasil.

${ }^{2}$ Professora da Faculdade de Enfermagem da Universidade Federal de Mato Grosso - UFMS - Campo Grande, (MS), Brasil. Membro do Grupo de Pesquisa Enfermagem, Saúde e Cidadania - Campo Grande (MS), Brasil.

${ }^{3}$ Professora da Faculdade de Enfermagem da Universidade Federal de Mato Grosso - UFMS - Campo Grande, (MS), Brasil. Vice-coordenadora do Grupo de Pesquisa Enfermagem, Saúde e Cidadania - Campo Grande (MS), Brasil.
} 


\section{INTRODUÇÃO}

Nosso propósito neste relato de experiência foi descrever como vem sendo realizada a consulta de enfermagem (CE) às mães e seus filhos até seis meses de idade, egressos do Ambulatório da Clínica Obstétrica do Hospital Universitário Júlio Müller, da Universidade Federal de Mato Grosso. Partimos do pressuposto que a CE é um espaço privilegiado para o estabelecimento de um diálogo profícuo entre a cultura e os saberes da população assistida com os saberes acadêmicos em saúde e enfermagem.

A idéia para repensar um processo aparentemente técnico como se apresentava a CE surgiu a partir de leituras sobre a teoria da Ação Comunicativa do filósofo alemão Jürgen Habermas. Este autor fez uma profunda reflexão epistemológica que colocou em cheque as questões que envolvem as matrizes positivistas $\mathrm{da}$ produção de conhecimento, nos lembrando que:

"O interesse que orienta o processo de conhecimento das ciências histórico-hermenêuticas é o da comunicação. O interesse técnico se enraiza nas estruturas da ação instrumental, baseada em regras técnicas, pelas quais o homem se relaciona com a natureza, submetendoa ao seu controle. O interesse comunicativo se enraíza nas estruturas da ação comunicativa, pela qual os homens se relacionam entre si, por meio de normas lingüisticamente articuladas, e cujo objetivo é o entendimento mútuo'(1).

\section{A CONSULTA DE ENFERMAGEM - UM PEQUENO HISTÓRICO}

A consulta de enfermagem surgiu em nosso país na década de sessenta e sua legalização ocorreu em 25 de junho de 1986 através da Lei n. ${ }^{\circ}$ 7.498/86, que regulamentou o Exercício da Enfermagem e estabeleceu essa atividade como privativa do enfermeiro. Em 1993, o Conselho Federal de Enfermagem (COFEN), através da Resolução COFEN/159, estabeleceu a obrigatoriedade da realização da consulta de enfermagem em todos os níveis de assistência à saúde em instituição pública ou privada ${ }^{(2)}$.

A consulta objetiva sistematizar, dar consistência, sentido, registro e memória à assistência de enfermagem nos três níveis da atenção à saúde humana, conforme preconiza a Lei n. ${ }^{\circ} 8080 / 1998$. É composta por quatro fases: a coleta dos dados, o estabelecimento dos diagnósticos de enfermagem, a fase da implementação de cuidados e a de avaliação dos resultados do plano de cuidados de enfermagem ${ }^{(2)}$.

No Ambulatório do hospital estudado, a CE já existe desde 1984. Desta época até o inicio dos anos 90, as enfermeiras docentes que atuavam no local adotaram o modelo clínico para realizar a CE. Neste relato, este modelo será caracterizado como aquele que:

"Valoriza a objetividade da clínica e nega a subjetividade do sujeito no processo saúde-doença. Sob o pretexto da busca da maior objetividade possivel, o exercício da clinica exige uma série de técnicas para neutralizar a interferência do social e da subjetividade de cada paciente no curso do tratamento"(3).

Frente aos questionamentos que a adoção deste modelo provocava entre as enfermeiras, estas sentiram necessidade de modificá-lo, para responder as especificidades que demandavam dessa clientela atendida.

Como havia um alto índice de ausências nas consultas ao longo dos seis primeiros meses de puerpério, que prejudicavam não só o lactente, mas também a mãe, pudemos constatar que o modelo clínico não respondia às necessidades da clientela e não as motivava a manter a regularidade necessária para evitar problemas comuns nesta fase da vida. Assim, passamos a repensar como fazer esse atendimento de forma compartilhada com aquelas mulheres que vivenciavam os processos de cuidar de si e de um lactente.

Encontramos nossas bases teóricas ao perceber que:

"Pessoas criam e desenvolvem fontes simbólicas de iluminação para os comportamentos e ações, porque precisam delas para encontrar seus apoios no mundo, e é também através dessas estruturas de significado que elas dão significado as suas experiências vividas"(4).

E ignorar estes aspectos significa ignorar o outro que procura por atendimento nos serviços de saúde. Para tanto, passamos a enfocar outros aspectos do cuidado ao binômio, valorizando a cultura e os saberes populares e procuramos, a partir desses elementos, criar um espaço de comunicação democrática e consensual que fizesse sentido para as mães, de forma que pudéssemos compartilhar nossas experiências e conhecimentos e ampliar o vínculo e a motivação de ambos os sujeitos do processo.

Por se tratar de uma experiência nova no espaço de trabalho já conhecido, começamos a documentar o processo de mudança na CE. A finalidade era produzir material escrito que nos apoiasse na avaliação das mudanças implantadas, seus resultados e, em continuidade, nos oferecesse subsídios para retomadas de condutas e estratégias em relação ao proposto.

Para garantir o acesso e o atendimento, enfatizamos a importância da primeira consulta até os 15 dias posteriores à alta hospitalar. A coleta de dados deu-se de julho a dezembro de 2001 no referido ambulatório. A técnica utilizada foi o registro em diários de campo das impressões verbalizadas pelas mulheres sobre o atendimento recebido, suas queixas, dúvidas, aprendizados, bem como os seus progressos em relação 
ao atendimento e às orientações feitas a cada consulta. Demos o mesmo tratamento às nossas percepções e impressões, e também estas foram registradas na seqüência de cada consulta, na medida do possível e ao final de cada dia de atendimento.

Ao final de seis meses, selecionamos 30 relatos de mulheres que freqüentaram o serviço, sendo o critério principal adotado para a seleção dos mesmos, a regularidade do comparecimento às consultas. Selecionamos, também, 24 registros relativos às nossas impressões profissionais durante os diversos procedimentos que fazem parte da consulta de enfermagem para as mães, e partimos para a avaliação final do trabalho realizado no ambulatório.

\section{DIALOGANDO COM OS SABERES E OS VALORES CULTURAIS DA POPULAÇÃO ATENDIDA}

Neste relato, nosso olhar centralizou-se nos conteúdos que revelassem as alterações na dinâmica do processo comunicativo por ser esse um aspecto que era motivo de queixas recorrentes, junto ao acesso e acolhimento do serviço. Traçamos, como objetivo, primeiro manter as consultas pelo menos até o $6^{\circ}$ mês de vida do bebê, e para conseguir tal intento, começamos valorizando as falas através do diálogo com a cultura relativa ao processo vivenciado pelas mulheres clientes do ambulatório.

Entender a lógica de um sistema cultural requer a compreensão da racionalidade subjacente na cultura dos cuidados puerperais populares ${ }^{(4)}$. Percebemos a necessidade de construir um processo de mão dupla, no qual ouvíamos as mulheres e, através de um exercício constante, reinterpretávamos os cuidados populares à luz do conhecimento acadêmico e os estimulávamos ou dialogávamos com as mulheres para adaptá-los ou mudálos, caso oferecessem riscos para a saúde da mãe ou do bebê.

Para redesenhar a consulta e alcançar o objetivo proposto, o material que se mostrou mais profícuo foi o que aborda a maternidade, o puerpério, e mesmo o autocuidado e os cuidados com bebês recém-nascidos e lactentes, como parte de um delicado processo sóciocultural no qual interferem vários elementos ${ }^{(4)}$ que são ligados ao imaginário cultural que perpassa as práticas de saúde nas comunidades, mas também sofre a influência das práticas profissionais ${ }^{(5)}$.

Ao interagir com a clientela do ambulatório, percebemos que os profissionais necessitavam incorporar outros valores, conceitos e atitudes que mantivessem a clientela como centro e que o profissional e o serviço deveriam funcionar mais como apoio e retaguarda para as necessidades de saúde por ela identificada.

Dessa maneira, pôde-se realizar o "estabelecimento não-coercitivo de relações intersubjetivas"(1), base para que o cuidado em saúde se efetivasse para além do que definimos como assistência clínica, ou tecnificada. Estabelecer relações não-coercitivas, e sim democráticas, demanda um outro modelo de poder, mais horizontalizado do que aquele que tem lugar hoje nas relações entre usuários e profissionais de saúde. Este agir parte do modelo de ação comunicativo, no qual o fenômeno do poder não consiste na instrumentalização de uma vontade alheia para os próprios fins, mas na formação de uma vontade comum, numa comunicação orientada para o entendimento recíprocos(1).

A escuta atenta se revelou como um pilar importante para que as mulheres se sentissem amparadas e seguras acerca das orientações que receberam. Essa estratégia concretizou um acolhimento diferenciado, baseado na emergência de novas formas de intersubjetividade entre clientela e enfermeiras-docentes, fundamentado na valorização da fala, das experiências e dúvidas das mulheres. Esse foi um fator decisivo na regularidade da freqüência e na permanência da clientela no ambulatório. Tivemos um índice de $20 \%$ de faltas do total de consultas ao longo do trabalho feito, sendo essas ausências nos dias agendados, remarcadas pela procura das clientes.

Dentre os elementos verbalizados pelas puérperas ao longo das consultas, destacaram-se a confiança nos conhecimentos de outras mulheres que já haviam passado pelo mesmo processo (como avós, irmãs e vizinhas), que revelaram várias permanências culturais relacionadas à dieta "correta" para a "mulher parida", adaptações alimentares para a mulher que vai amamentar, que incluem interdições a certos alimentos, os cuidados com o coto umbilical, com a ferida operatória e com as mamas.

Para valorizar os conteúdos culturais trazidos pelas mulheres, como de que certos alimentos são inadequados para o seu consumo por serem "remosos", fomos buscar a matriz cultural que os definia e quais eram esses alimentos e o que significavam. Pudemos perceber que eles tinham algo em comum, mas se diferenciavam, de acordo com a comunidade de origem das clientes. "Remoso" significava para todas "gorduroso", e há a crença que o alimento com essa natureza predispõe a mulher a doenças que foram definidas por sintomas e sinais como "febres", "sangramento malcheiroso", "inchaço e pus no pique", e também causam dificuldades no aleitamento, pois o "leite não sai, o peito empedra" ou quando sai "vem com sangue ou pus".

Esse quadro relatado coincide com os sinais identificados como "recaída", isso significando que evitar esses alimentos é de grande importância. Mas muitas das puérperas atendidas eram moradoras das regiões ribeirinhas, onde a principal fonte de proteína é o peixe. Orientamos, então, que retirassem toda a gordura visível 
e que ingerissem a carne, pois o que fazia mal era a gordura, sugestão que foi bem aceita, pois foi negociado caso a caso.

Identificamos, ainda, vários conteúdos culturais relacionados à amamentação, e dentre eles nos chamou a atenção o uso de um pente para "pentear a mama", para estimular o leite a descer, prática esta que nos pareceu inócua, desde que fosse feita com pente limpo e com suavidade. Pudemos perceber, também, que em algumas demonstrações desse cuidado, feito por algumas mulheres, $\mathrm{o}$ ato de pentear as mamas era feito com fricções suaves, o que de certa forma massageava as mamas, possibilitando a drenagem do leite retido.

Os cuidados com o coto umbilical são, de longe, os mais variados e diversos, mas ainda há a crença na importância da faixa abdominal para evitar que o "umbigo salte para fora". Por morarmos em uma região com altas temperaturas ambientais, o uso dessa faixa pode predispor a infecção no coto umbilical, pela umidade e calor local que provoca e, assim, optamos por esclarecer que a hérnia umbilical acontece por razões outras que não são evitadas pelo uso da compressão local, e que, dependendo da sua extensão, deverá ser corrigida cirurgicamente. Houve, assim, uma adesão progressiva ao abandono da faixa através do entendimento dessas mulheres acerca destes riscos.

Partimos do pressuposto que as mulheres que adquirissem segurança nos procedimentos mais comuns e também um conhecimento respaldado nas evidências de bons resultados nas atividades relativas ao processo que vivenciavam, seriam replicadoras de conteúdos e práticas mais seguras, para outras mulheres da sua coletividade.

O temor de cuidar do filho ${ }^{(6)}$ é maior quando nasce o primogênito, mas pode também ocorrer nas gestações seguintes. Mas com a nova abordagem adotada na prática da consulta, a aceitação da mesma pelas mulheres foi muito positiva, uma vez que seus referenciais culturais foram respeitados, e elas foram valorizadas também como sujeitos de conhecimento sobre seus processos culturais e seu corpo.

\section{CONSIDERAÇÕES FINAIS}

Não se podem desconsiderar os critérios de racionalidade que dirigem a cultura das coletividades às quais as mães pertencem, sob risco de não haver a adesão desejada ao programa de acompanhamento como prevíamos. Incorporar esses elementos populares significa ampliar a abordagem profissional na consulta, e não reduzi-la como pode parecer à primeira vista, ao conhecimento cientificamente produzido.

No relacionamento com as puérperas, por estarem em um período permeado por enormes mudanças e novas responsabilidades, pudemos perceber que a aproximação entre estas e os profissionais é de extrema importância, para permitir a comunicação e criar vínculos.

Ao valorizarmos o conhecimento popular acerca do puerpério, amamentação e cuidados com o recém nascido e lactente da nossa clientela, pudemos então compreender as vivências das mulheres e entender os sentimentos contraditórios, os diferentes valores e os conhecimentos trazidos pelas mulheres. Compreendemos, também, que estes se diferenciavam de acordo com a interpretação da cultura em cada comunidade específica, e que através do novo modelo de atenção implementado, baseado na produção de consensos, não só incorporamos novos conhecimentos como também ampliamos a autoconfiança de ambos os sujeitos do processo - população e profissionais de enfermagem nos novos saberes produzidos nesta interação.

\section{REFERÊNCIAS}

1. Habermas J. O conceito de poder em Hannah Arendt. In: Habermas J, Freitag B, Rouanet SP, organizadores. Habermas: sociologia. São Paulo: Atica; 1980. p. 100-18. [Coleção Grandes Cientistas Sociais ,15].

2. Resolução COFEN-159/1993. Dispõe sobre a consulta de Enfermagem. [citado 2006 Ago 07]. Disponível em: http:/ /www.portalcofen.com.gov.br/- novoportal/.

3. Campos GWS. Reforma da reforma: repensando a saúde. 2a ed. São Paulo: Hucitec; 1997.

4. Monticelli M. Nascimento como um rito de passagem: abordagem para o cuidado às mulheres e recém-nascidos. São Paulo: Robe Editorial; 1997.

5. Maldonado MT. Sementes do amor: educar crianças de $0 \mathrm{a}$ 3 anos para a paz. São Paulo: Planeta do Brasil; 2003.

6. Kitzinger S. Mães: um estudo antropológico da maternidade. Lisboa: Presença; 1978. 